\title{
Analysis of Crack Tip Opening Displacement under Mixed Mode Fracture Using Fem Technique
}

\author{
Veerendra Patle $^{1}$, Dr. Shailendra Singh Bhadauria ${ }^{2}$, Abhishek jain $^{3}$ \\ ${ }^{1}$ Corresponding Author: M. Tech. Scholar, Product Design and Development, BUIT, Bhopal, India \\ ${ }^{2}$ Asst. Professer, Department of Industrial production Engineering NIT Jalandhar, India) \\ ${ }^{3}$ Asst. Professors, Department of Mechanical Engineering, BUIT Bhopal, M.P, India)
}

\begin{abstract}
Now-a-days it is very difficult to find exact failure and fracture mechanism in complex devices. This analysis gives better approach towards the modes of failure and relation between the crack opening displacements with stress triaxility, which strongly affects the ductile fracture of the body for compact tension shear type of geometry (CTS specimen). Also the effect of mode mixity ratio on the size of the material and other fracture parameters has been analysed. In this analysis the behavior of crack with respect to load in mode I and mixed mode II is described and FEM technique used for stress distribution. Variation of load inclination angle with respect to stress triaxility, variation of crack tip opening displacement with stress triaxility in the compact tension specimen is also discussed with findings.
\end{abstract}

Key Words: Crack opening displacement EPFM, LEFM, Mixed mode, Stress triaxiality

\section{INTRODUCTION}

This analysis deals with ductile material fracture where role of plastic deformation is very important. In plastic deformation crack propagates slowly and results to fracture. The mainstream of numerical analysis of crack development in CTS specimen focuses on the behavior of crack with respect to different fracture parameter which is very essential in the field of fracture mechanics. One of the significant researches has been done by Mahanti ET. Al. (1990) [1] investigated that the crack opening angle (COA) remained nearly constant during the whole stable growth. The concept of a critical crack opening displacement as a fracture criterion for the study of crack initiation in situations where significant plastic deformation precedes fracture. Under such conditions the stresses around the crack tip reach the critical value and therefore fracture is controlled by the amount of plastic strain. Robinson (1976)[2] have investigated that the effects of specimen type (precracked tension or bend) on the relationship between the J-integral and the crack tip opening displacement (COD) and on crack initiation values of $\mathrm{J}$ and COD. No significant effect of specimen type was noted. Mageed and Pandey (2001)[3] investigated the Mixed mode static and cyclic crack initiation and crack path experimentally in 2024T3 Al-Alloy sheets by using a center oblique cracked panel geometry under uniaxial loading. It was found that crack initiation angle as well as crack growth profile are different for cyclic loading as compared to the static loading under a mixed mode (mode I and II combined) loading situation. Srinivas and Vasudevan (1993)[4] Mixed mode crack growth behavior was studied. Experiments were conducted on Compact Tension Shear (CTS) specimens at different angles including both mode I and mode II test conditions, and in both static and fatigue conditions. The fracture angle was observed to increase with decrease in crack angle. The angle of crack propagation or the fracture angle is not a sensitive function of the applied load. Robinson and Tetelman (1976) [5] described a method that can be used to measure the values of crack tip opening displacement (COD) at any section of a pre-cracked or slotted specimen. Transverse contraction results in smaller COD values, for a particular clip gauge displacement, at the outside than at the specimen midsection. An equation is presented relating COD to longitudinal notch root strain for Charpy specimens with root radius 0.002 in. COD and notch root strain are found to be not directly proportional. This finding is discussed in relation to the concept of a "miniature tensile specimen" at the notch root. Maiti and Mourad (2000) [6] has been studied the Stable crack growth in mixed mode through doubly stiffened and unstiffened compact tension(CT) specimens of D16AT aluminium alloy theoretically and experimentally. The study reported that in the un stiffened case, load acts remote from the crack tip. In the stiffened case, there is a definite restraint on the crack opening, acting close to the crack tip. In both the cases the extent of crack grow this small and it occurs almost along a straight course, and there is small scale yielding. Maiti and Salva (2001) [7] presented mode I stable crack growth results under static loading through a symmetrically stiffened compact tension specimen of an aircraft grade aluminium alloy (D16AT). . From the finite element analysis. It is observed that the $\mathrm{J}$ integral increases as the crack extends. The plastic zone also grows as the stable extension progresses; the growth is more or less maximum along the line of stable crack extension. Maiti et al. (2008) [8] found that both initiation and the maximum loads can be predicted reasonably accurately by the FEA employing CTOA/COD criterion. $P$ versus LLD diagrams predicted by finite element analysis compare closely with experimental curves for both modes I and mixed mode, though 
there is a difference in the theoretical and experimental LLD at the later stages of crack growth. Bhattacharya and Kumar (1991) [9] observed that the analytical approach quantifies the difference in CTOD values between .the two methods as a function of slow crack growth. The difference tends to diminish with extent of crack growth as the crack tip approaches the plastic hinge point. Shailendra Singh Bhadauria et al. (2009) [10] discussd the effects of stress triaxiality on yielding behavior of anisotropic materials. The results obtained give the set of principal stresses along with corresponding critical tri axiality which is the maximum value at which the material can sustain without failure. If tri axiality extends furthermore the material will go to plastic deformation and may prone to failure. Shailendra Singh Bhadauria et al. (2012) [11] found that increase in Poisson's ratio leads to increase in stress triaxiality, thus for particular set of principal stresses, higher Poisson's ratio have prone to initiate crack as compared to lower Poisson's ratio. Shailendra Singh Bhadauria et al. (2010) [12] The study deals with the prediction of crack initiation angle under mixed mode (I/II) fracture using finite element using $\mathrm{K}$ based approach. It was observed that the stiffness of the material increases followed by shoot-up in stress tri axiality thus trigger the chance of brittle fracture. Roy et al (2000) [13] determined the effect of constraint on ductile fracture initiation from a notch tip under mode I and mixed mode (involving modes I and II) loading is investigated. The mode I fracture toughness obtained from the CTS specimen with $a / w=0.5$ is significantly higher than that determined using a deeply cracked $(a / w=0.7)$ CTS specimen. As the mode II component of loading is increased, the crack tip constraint appears to have only a marginal effect on the fracture toughness. The crack extension takes place by void growth and coalescence with the original crack tip, a mechanism for which the crack-tip strain is responsible. Among the many proposed methods, the von Mises relationship is most appealing from the stand point of continuum calculation and experimental data treatment and is almost universally used by the engineers. As it is clear from the definition of stress triaxility that, it is the ration of hydrostatic pressure to the Von-mises stresses. Mathematical expression for Von-mises triaxial stresses: Present work is the extension of the experimental work done by Maiti and Mohanti (2000). They have done experimental analysis on CT specimen and determined the initiation and maximum load which a material can sustain. The study was carried out for two crack inclination angles. Present study will be based on five different crack initiation angle with the FE study on mode I and mixed mode stable crack growth under static loadings using stainless steel of grade 304 and Aluminum alloy Al-6061. The compact tension shear (CTS) type of geometry as shown in Fig. 1 will be used for both the materials.

$$
\sigma_{y}=\sqrt{\frac{1}{2}\left[\left(\sigma_{1}-\sigma_{x}\right)^{2}+\left(\sigma_{2}-\sigma_{x}\right)^{2}+\left(\sigma_{x}-\sigma_{y}\right)^{2}\right]}
$$

The tests were carried out using the Compact Tension Shear (CTS) specimens. The loading was given as per the modified mixed mode loading device which was developed by Richard and Benitz (1983). In this case numerical analysis technique is used. Two sets of CTS specimens, each containing 5 samples, are made from stainless steel of grade 304 with thickness of $1.2 \mathrm{~mm}$ and $3.0 \mathrm{~mm}$ respectively. In addition to this, two more sets of specimens, each containing 5 pieces, are made from commercial Aluminum alloy (Al-6061) with thickness of $3.0 \mathrm{~mm}$ and $5.0 \mathrm{~mm}$ respectively. Grade 304 is the standard " $18 / 8$ " stainless and is the most versatile and widely used of all stainless steel.

\section{Basic Principle}

Generally engineering materials fails in ductile, brittle, fatigue etc. In all, mechanism of fracture is different. In ductile fracture the deformation is concentrated in the region of plastic instability until the crystal separates along a line or a point. In ductile fracture there are three modes. First is Opening mode in which the crack surfaces separate symmetrically with respect to the planes $x y$ and $x z$. In this case $v \neq 0$ another mode is sliding mode in which the crack surfaces slide relative to each other symmetrically with respect to the plane $x y$ and skew-symmetrically with respect to the plane xz. In this case $v=w=0$ and $u \neq 0$ after that Tearing mode comes into picture in which the crack surfaces slide relative to each other skew symmetrically with respect to both planes $x y$ and $x z$. In this case $u=v=0$ and $w \neq 0$. A measure of the amount of crack tip plastic strain is the separation of the crack faces or crack opening displacement (COD), especially very close to the crack tip as shown in Figure 1.6. It is thus expected that crack extension will begin when the crack opening displacement reaches some critical value which is characteristic of the material at a given temperature, plate thickness, strain rate and environmental conditions. Where $\mathrm{u}, \mathrm{v}$ and $\mathrm{w}$ denote the displacement components along the axes $\mathrm{x}, \mathrm{y}$ and $\mathrm{z}$ - axes respectively. Thus, the strains and stresses depend only on the variables $\mathrm{x}$ and $\mathrm{y}$. The expression for stress triaxility is given by

$$
\frac{\sigma_{-}}{\sigma_{-}}=\frac{\left(\sigma_{1}+\sigma_{x}+\sigma_{x}\right) / 3}{\frac{1}{\sqrt{2}} \sqrt{\left[\left(\sigma_{1}-\sigma_{z}\right)^{2}+\left(\sigma_{x}-\sigma_{x}\right)^{2}+\left(\sigma_{x}-\sigma_{1}\right)^{2}\right]}}
$$




\section{PROBLEM FORMULATION}

The specimen used for the numerical analysis as shown in figure. Tests are performed by applying five different loads at different angles and stress intensity factor, crack opening displacement, crack opening angle, crack initiation load, breaking load, breaking has been calculated. Problem is idealized as two dimensional, therefore, PLANE183 (quadrilateral 8 noded structural element) having two degrees of freedom in $\mathrm{x}$ and $\mathrm{y}$ directions has been used for FE modeling. It is a higher order element and possesses quadratic displacement behavior and is well suited for modeling irregular geometry as shown in Figure IIa. In addition to this, element behavior was chosen as plane stress (as the problem is 2D). The element thickness is taken as $1.2 \mathrm{~mm}$ and $3 \mathrm{~mm}$ for SS304 and 3mm and $5 \mathrm{~mm}$ for Al-6061.

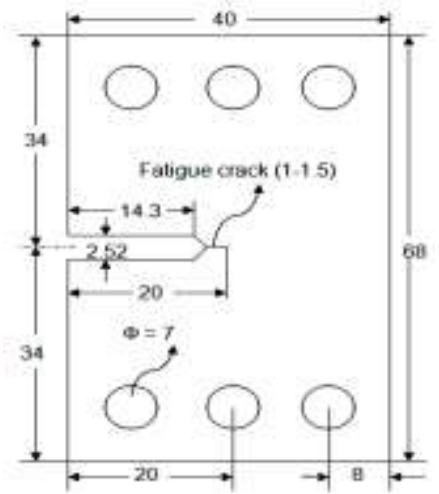

Figure -1 Geometry of CTS specimen (All dimensions in $\mathrm{mm}$ )

\section{METHODOLOGY}

In the case of mixed mode fracture analysis full model of the CTS specimen is analyzed using ANSYS 12 software depicted. The problem is idealized as 2D plane stress and the geometry is modeled using 93 keypoints with keypoint 49 being the crack tip. Key points 7 and 8 are coincident such that each one belonging to opposite crack face near crack tip. Key point 8 and 49 are $1 \mathrm{~mm}$ apart showing fatigue crack. Three holes of diameter $7 \mathrm{~mm}$ are provided on top and bottom edges of the CTS specimen in order to define contact for loading pin. Boundary condition is prescribed on the bottom pilot node no. 38950 presented at the centre of middle hole which is restrained in the $\mathrm{x}$ and $\mathrm{y}$-direction. Uniformly distributed load at which the crack initiation took place is applied on single pilot node no. 38949 placed at the center of top middle hole which is in contact with the surface of all the three holes. The contact defined is of surface to node type. Material was modeled as a linear isotropic material having elastic modulus of $2.7 \times 10^{5} \mathrm{~N} / \mathrm{mm}^{2}$ and Poisson's ratio 0.28 for stainless steel grade 304 and modulus of elasticity of $7.2 \times 10^{4} \mathrm{~N} / \mathrm{mm}^{2}$ and Poisson's ratio 0.33 for Aluminum alloy (Al 6061) which was obtained experimentally.
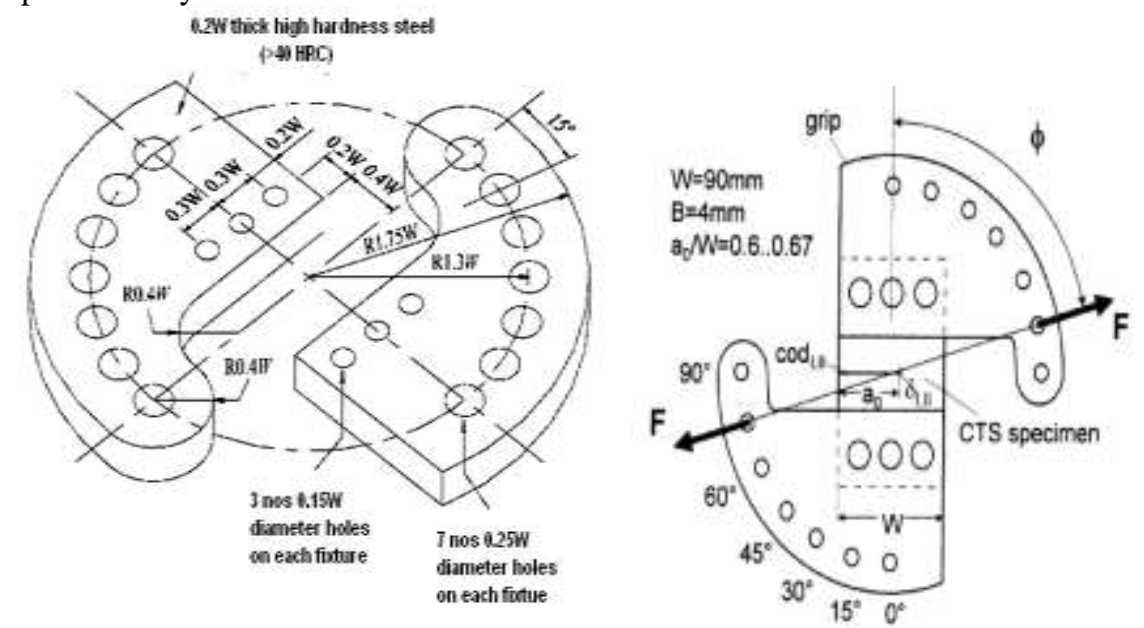

(a) Design of loading device (b) Device of mixed mode tests with CTS specimen

Fig 2 - Geometry of loading device 


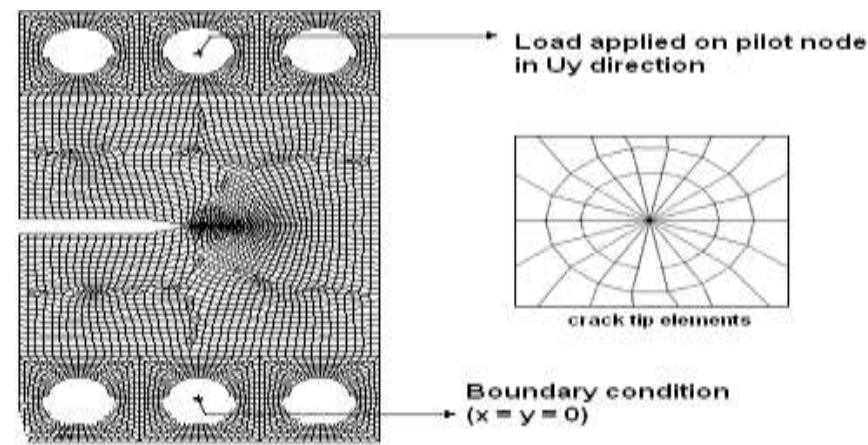

Fig -3 FE mesh of CTS specimen with crack tip mesh elements

Mathematical expresions for the calculation of Stress triaxility and CTOD are given by In terms of polar coordinates $r$ and $\theta$ at the crack tip, the stress components of the stress field can be written as:

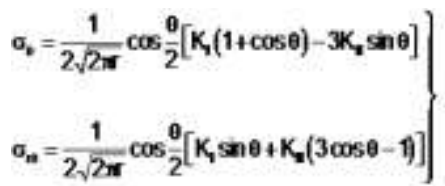

The rectangular displacement components in $\mathrm{u}_{\mathrm{x}}$ and $\mathrm{u}_{\mathrm{y}}$ direction at crack tip are given by:

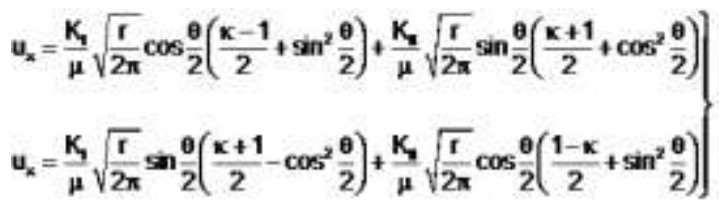

In the above equation, KI and KII are, respectively, the mode I and mode II stress intensity factors at the crack tip, $\mu=E / 2(1+v)$ is the shear modulus, $E$ is the Young's modulus and $\kappa=(3-v) /(1+v)$ is for the plane stress condition. The CTOD at the crack tip $(\delta)$ is the magnitude of the relative displacement vector between the upper and lower crack faces at a fixed distance behind the main crack tip. In particular, at a distance of $\mathrm{xc}$ behind the crack tip, we have

$$
\begin{aligned}
& \delta=\sqrt{\left[u_{x}\left(x_{c_{1}} 0^{+}\right)-u_{x}\left(x_{c_{1}} 0^{-}\right)\right]^{2}\left[u_{y}\left(x_{c_{1}} 0^{+}\right)-u_{y}\left(x_{c_{1}} 0^{-}\right)\right]^{2}} \\
& \delta=\frac{\kappa+1}{\mu} \sqrt{\frac{x_{c}}{2 \pi}}\left(K_{1}^{2}+K_{i}^{2}\right)^{1 / 2}
\end{aligned}
$$

Where subscripts "+" and "-" imply that the displacement component is for the upper and lower crack surface (where $\mathrm{y}=0$ ). The opening and shearing components of the current CTOD are denoted by $\delta_{\mid}$and $\delta_{\|}$ respectively and are given by:

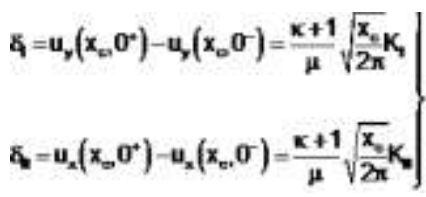

the mixity ratio is defined by:

$$
\mathrm{M}_{\mathrm{e}}=\frac{2}{\pi} \arctan \left(\frac{\mathrm{K}_{\mathrm{I}}}{\mathrm{K}_{\mathrm{II}}}\right)
$$

and the crack tip displacement vector is given by:

$$
\delta_{v}=\sqrt{\delta_{1}^{2}+\delta_{\| I}^{2}}
$$




\section{Tables}

Table 1 CTOD at crack initiation load and maximum load for SS304 (Thickness $=1.2 \mathrm{~mm}$ )

\begin{tabular}{|c|c|c|c|c|c|c|c|c|}
\hline $\begin{array}{c}\text { Angle } \\
(\beta)\end{array}$ & \multicolumn{2}{|c|}{$\begin{array}{c}\text { Load } \\
(\mathrm{kN})\end{array}$} & \multicolumn{2}{|c|}{$\begin{array}{c}\text { Opening component } \\
\left(\delta_{1}\right)\end{array}$} & \multicolumn{2}{c|}{$\begin{array}{c}\text { Opening component } \\
\left(\delta_{2}\right)\end{array}$} & \multicolumn{2}{c|}{$\begin{array}{c}\text { Total CTOD } \\
(\delta)\end{array}$} \\
\hline & $\mathrm{P}_{\mathrm{i}}$ & $\mathrm{P}_{\max }$ & $\mathrm{P}_{\mathrm{i}}$ & $\mathrm{P}_{\max }$ & $\mathrm{P}_{\mathrm{i}}$ & $\mathrm{P}_{\max }$ & $\mathrm{P}_{\mathrm{i}}$ & $\mathrm{P}_{\max }$ \\
\hline $0^{\circ}$ & 5.49 & 7.47 & $\begin{array}{c}1.07 \times 10^{-} \\
5\end{array}$ & $1.50 \times 10^{-6}$ & 0 & 0 & $1.07 \times 10^{-5}$ & $\begin{array}{c}1.50 \times \mathrm{x} \\
10^{-6}\end{array}$ \\
\hline $15^{\circ}$ & 4.85 & 6.95 & $\begin{array}{c}9.68 \times 10^{-} \\
6\end{array}$ & $1.38 \times 10^{-6}$ & $\begin{array}{c}5.43 \times \\
10^{-7}\end{array}$ & $7.77 \times 10^{-7}$ & $9.69 \times 10^{-6}$ & $\begin{array}{c}1.39 \times \\
10^{-6}\end{array}$ \\
\hline $30^{\circ}$ & 4.02 & 6.68 & $\begin{array}{c}8.45 \times 10^{-} \\
6\end{array}$ & $1.40 \times 10^{-6}$ & $\begin{array}{c}1.01 \times \\
10^{-6}\end{array}$ & $1.69 \times 10^{-6}$ & $8.51 \times 10^{-6}$ & $\begin{array}{c}1.41 \times \mathrm{x} \\
10^{-6}\end{array}$ \\
\hline $45^{\circ}$ & 3.9 & 6.26 & $\begin{array}{c}8.80 \times 10^{-} \\
6\end{array}$ & $1.41 \times 10^{-6}$ & $\begin{array}{c}1.82 \times \\
10^{-6}\end{array}$ & $2.92 \times 10^{-6}$ & $8.89 \times 10^{-6}$ & $\begin{array}{c}1.44 \times \\
10^{-6}\end{array}$ \\
\hline $60^{\circ}$ & 3.32 & 5.47 & $\begin{array}{c}7.74 \times 10^{-} \\
6\end{array}$ & $1.27 \times 10^{-6}$ & $\begin{array}{c}2.77 \times \\
10^{-6}\end{array}$ & $4.56 \times 10^{-6}$ & $8.22 \times 10^{-6}$ & $\begin{array}{c}1.35 \times \\
10^{-6}\end{array}$ \\
\hline
\end{tabular}

Table 2 CTOD at crack initiation load and maximum load for SS304 (Thickness $=3 \mathrm{~mm}$ )

\begin{tabular}{|c|c|c|c|c|c|c|c|c|}
\hline \multirow[t]{2}{*}{$\begin{array}{l}\text { Angle } \\
(\beta)\end{array}$} & \multicolumn{2}{|c|}{$\begin{array}{l}\text { Load } \\
(\mathrm{kN})\end{array}$} & \multicolumn{2}{|c|}{$\begin{array}{l}\text { Opening component } \\
\qquad\left(\delta_{1}\right)\end{array}$} & \multicolumn{2}{|c|}{$\begin{array}{l}\text { Opening component } \\
\qquad\left(\delta_{2}\right)\end{array}$} & \multicolumn{2}{|c|}{$\begin{array}{l}\text { Total CTOD } \\
\qquad(\delta)\end{array}$} \\
\hline & $\mathrm{P}_{\mathrm{i}}$ & $\mathrm{P}_{\max }$ & $P_{i}$ & $\mathrm{P}_{\max }$ & $\mathrm{P}_{\mathrm{i}}$ & $\mathrm{P}_{\max }$ & $\mathrm{P}_{\mathrm{i}}$ & $\mathrm{P}_{\max }$ \\
\hline $0^{\circ}$ & 01 & 3 & $8.63 \underset{6}{8} 10^{-}$ & $1.25 \times 5 \times 10^{-}$ & 0 & 0 & $8.62 \underset{6}{8} \times 10^{-}$ & $1.25 \times 5 \times 10^{-}$ \\
\hline 15 & & 1 & $8.56 \times \underset{6}{8} \times 10^{-}$ & $1.24 \underset{5}{x} 10^{-}$ & $\underset{7}{4.84 \times 10}$ & 6.9 & $8.57 \underset{6}{x} 10^{-}$ & $1.24 \underset{5}{x} 10^{-}$ \\
\hline $30^{\circ}$ & & & $8.72 \underset{6}{2} 10^{-}$ & $1.27 \underset{5}{\mathrm{x}} 10^{-}$ & $\underset{6}{1.05 \times 10}$ & $1.51 x$ & $8.78 \underset{6}{x} 10^{-}$ & $1.28 \times 5 \times 10^{-}$ \\
\hline $45^{\circ}$ & 33 & 55 & $8.88 \times \underset{6}{x} 10^{-}$ & $1.31 \times 5 \times$ & $1.83 \times 6$ & $2.72 x$ & $9.06 \underset{6}{9} \times 10^{-}$ & $1.34 \underset{5}{x} 10^{-}$ \\
\hline$\overline{60}$ & 8.82 & 13.42 & $8.23 \times \underset{6}{x} 10^{-}$ & $1.25 \times 5 \times 10^{-}$ & $2.94 \underset{6}{x} 10$ & $4.47 \times 10^{-6}$ & $8.74 \underset{6}{x} 10^{-}$ & $1.33 \times 5 \times 10^{-}$ \\
\hline
\end{tabular}

Table 3 CTOD at crack initiation load and maximum load for Al-6961 (Thickness $=3 \mathrm{~mm}$ )

\begin{tabular}{|c|c|c|c|c|c|c|c|c|}
\hline $\begin{array}{c}\text { Angle } \\
(\beta)\end{array}$ & \multicolumn{2}{|c|}{$\begin{array}{c}\text { Load } \\
(\mathrm{kN})\end{array}$} & \multicolumn{2}{c|}{$\begin{array}{c}\text { Opening component } \\
\left(\delta_{1}\right)\end{array}$} & \multicolumn{2}{c|}{$\begin{array}{c}\text { Opening component } \\
\left(\delta_{2}\right)\end{array}$} & \multicolumn{2}{c|}{$\begin{array}{c}\text { Total CTOD } \\
(\delta)\end{array}$} \\
\hline & $\mathrm{P}_{\mathrm{i}}$ & $\mathrm{P}_{\max }$ & $\mathrm{P}_{\mathrm{i}}$ & $\mathrm{P}_{\max }$ & $\mathrm{P}_{\mathrm{i}}$ & $\mathrm{P}_{\max }$ & $\mathrm{P}_{\mathrm{i}}$ & $\mathrm{P}_{\max }$ \\
\hline $0^{\circ}$ & 3.82 & 4 & $1.12 \times 10^{-5}$ & $1.17 \times 10^{-5}$ & 0 & 0 & $8.12 \times 10^{-5}$ & $1.17 \times 10^{-5}$ \\
\hline $15^{\circ}$ & 3.2 & 3.72 & $9.51 \times 10^{-6}$ & $1.11 \times 10^{-5}$ & $5.3 \times 10^{-7}$ & $6.15 \times 10^{-7}$ & $9.53 \times 10^{-6}$ & $1.11 \times 10^{-5}$ \\
\hline $30^{\circ}$ & 2.51 & 3.41 & $7.89 \times 10^{-6}$ & $1.07 \times 10^{-5}$ & $9.36 \times 10^{-7}$ & $1.27 \times 10^{-6}$ & $7.95 \times 10^{-6}$ & $1.07 \times 10^{-5}$ \\
\hline $45^{\circ}$ & 1.89 & 2.56 & $6.36 \times 10^{-6}$ & $8.64 \times 10^{-6}$ & $1.31 \times 10^{-6}$ & $1.77 \times 10^{-6}$ & $6.5 \times 10^{-6}$ & $8.82 \times 10^{-6}$ \\
\hline $60^{\circ}$ & 1.21 & 2.16 & $4.21 \times 10^{-6}$ & $7.55 \times 10^{-6}$ & $1.5 \times 10^{-6}$ & $2.67 \times 10^{-6}$ & $4.47 \times 10^{-6}$ & $8.01 \times 10^{-6}$ \\
\hline
\end{tabular}

Table 4 CTOD at crack initiation load and maximum load for Al-6961 (Thickness $=5 \mathrm{~mm}$ )

\begin{tabular}{|c|c|c|c|c|c|c|c|c|}
\hline \multirow[t]{2}{*}{$\begin{array}{c}\text { Angle } \\
(\beta)\end{array}$} & \multicolumn{2}{|c|}{$\begin{array}{l}\text { Load } \\
(\mathrm{kN})\end{array}$} & \multicolumn{2}{|c|}{$\begin{array}{l}\text { Opening component } \\
\qquad\left(\delta_{1}\right)\end{array}$} & \multicolumn{2}{|c|}{$\begin{array}{l}\text { Opening component } \\
\qquad\left(\delta_{2}\right)\end{array}$} & \multicolumn{2}{|c|}{$\begin{array}{l}\text { Total CTOD } \\
\qquad(\delta)\end{array}$} \\
\hline & $P_{i}$ & $P_{\max }$ & $\mathrm{P}_{\mathrm{i}}$ & $P_{\max }$ & $P_{i}$ & $P_{\max }$ & $P_{i}$ & $\mathrm{P}_{\max }$ \\
\hline $0^{\circ}$ & 4.56 & 5.44 & $\begin{array}{c}7.99 \mathrm{x} \\
10^{-6}\end{array}$ & $\begin{array}{c}9.54 \mathrm{x} \\
10^{-6}\end{array}$ & 0 & 0 & $\begin{array}{c}7.99 \mathrm{x} \\
10^{-6}\end{array}$ & $\begin{array}{c}7.99 \mathrm{x} \\
10^{-6}\end{array}$ \\
\hline $15^{\circ}$ & 4.43 & 5.36 & $\begin{array}{c}7.92 x \\
10^{-6}\end{array}$ & $\begin{array}{c}9.58 \times \\
10^{-6}\end{array}$ & $4.43 \times 10^{-7}$ & $5.3 \times 10^{-7}$ & $\begin{array}{c}7.94 \mathrm{x} \\
10^{-6}\end{array}$ & $\begin{array}{c}7.94 \times x \\
10^{-6}\end{array}$ \\
\hline $30^{\circ}$ & 3.92 & 4.86 & $\begin{array}{c}7.39 \mathrm{x} \\
10^{-6} \\
\end{array}$ & $\begin{array}{c}9.14 \mathrm{x} \\
10^{-6} \\
\end{array}$ & $8.8 \times 10^{-7}$ & $1.1 \times 10^{-6}$ & $\begin{array}{c}7.45 \mathrm{x} \\
10^{-6} \\
\end{array}$ & $\begin{array}{c}7.45 \mathrm{x} \\
10^{-6} \\
\end{array}$ \\
\hline $45^{\circ}$ & 3.41 & 4.26 & $6.9 \times 10^{-6}$ & $\begin{array}{c}8.64 \mathrm{x} \\
10^{-6} \\
\end{array}$ & $1.42 \times 10^{-6}$ & $1.77 \times 10^{-6}$ & $\begin{array}{c}7.04 \mathrm{x} \\
10^{-6} \\
\end{array}$ & $\begin{array}{c}7.04 \times x \\
10^{-6}\end{array}$ \\
\hline $60^{\circ}$ & 2.92 & 3.47 & $\begin{array}{c}6.12 \mathrm{x} \\
10^{-6}\end{array}$ & $\begin{array}{c}7.27 \times \\
10^{-6} \\
\end{array}$ & $2.15 \times 10^{-6}$ & $2.58 \times 10^{-6}$ & $\begin{array}{c}8.48 \mathrm{x} \\
10^{-6}\end{array}$ & $\begin{array}{c}6.48 \mathrm{x} \\
10^{-6}\end{array}$ \\
\hline
\end{tabular}




\section{Results}

The CTOD vector along the plane of crack is determined using Eqs. Mentioned above and the values obtained are provided in Table (1 to 4). Figure 4 shows that triaxiality increases with increase in CTOD in case of Al6061. Figure 4 shows that the triaxiality first increases for both CTS specimens of SS-304 having thickness of $1.2 \mathrm{~mm}$ and $3 \mathrm{~mm}$ and thereafter it decreases to a minimum value of 0.618 and achieves its maximum value. The trend of variation of triaxiality and load inclination angle with mode mixity ratio is depicted in Figure 5 and Figure 6 respectively. It is found that $\mathrm{Me}$ is independent of material property and geometry but dependent upon applied load. Contour plot of equivalent von mises stress can be seen in Figures ( 7 to 11). This contour shows the inclination of plastic zone as per load inclination angle.

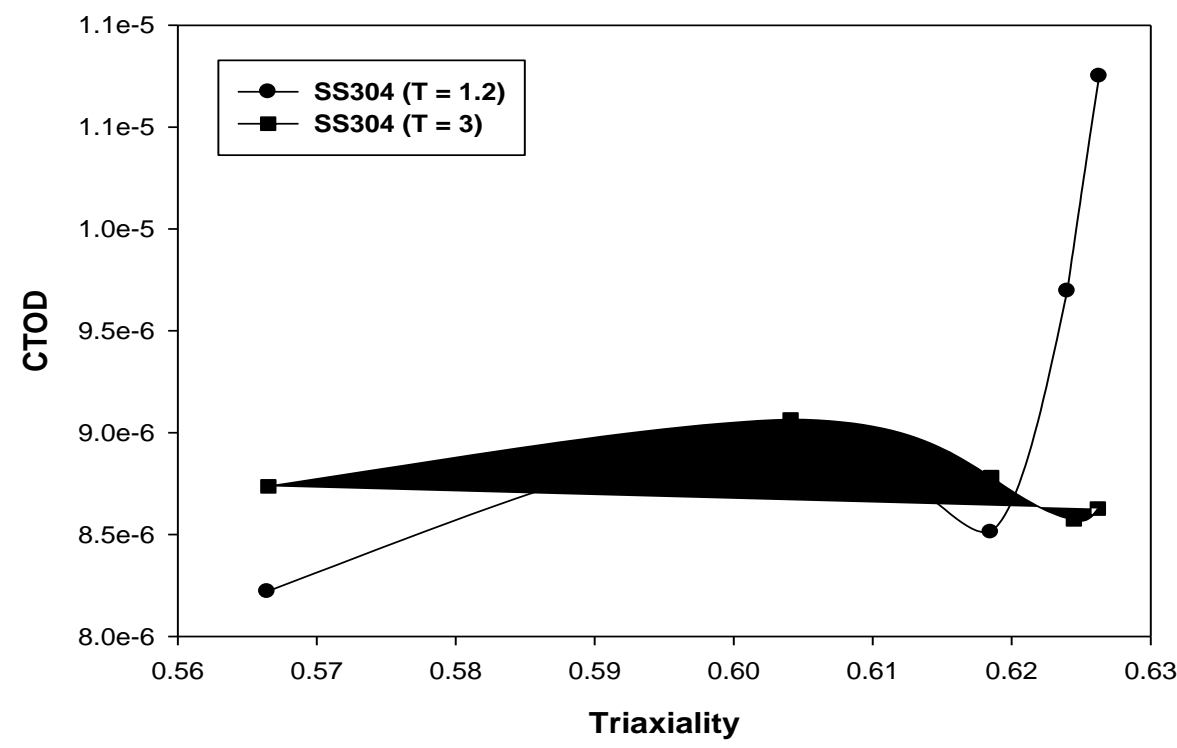

Fig 4 Variation of CTOD with stress triaxiality for SS-304

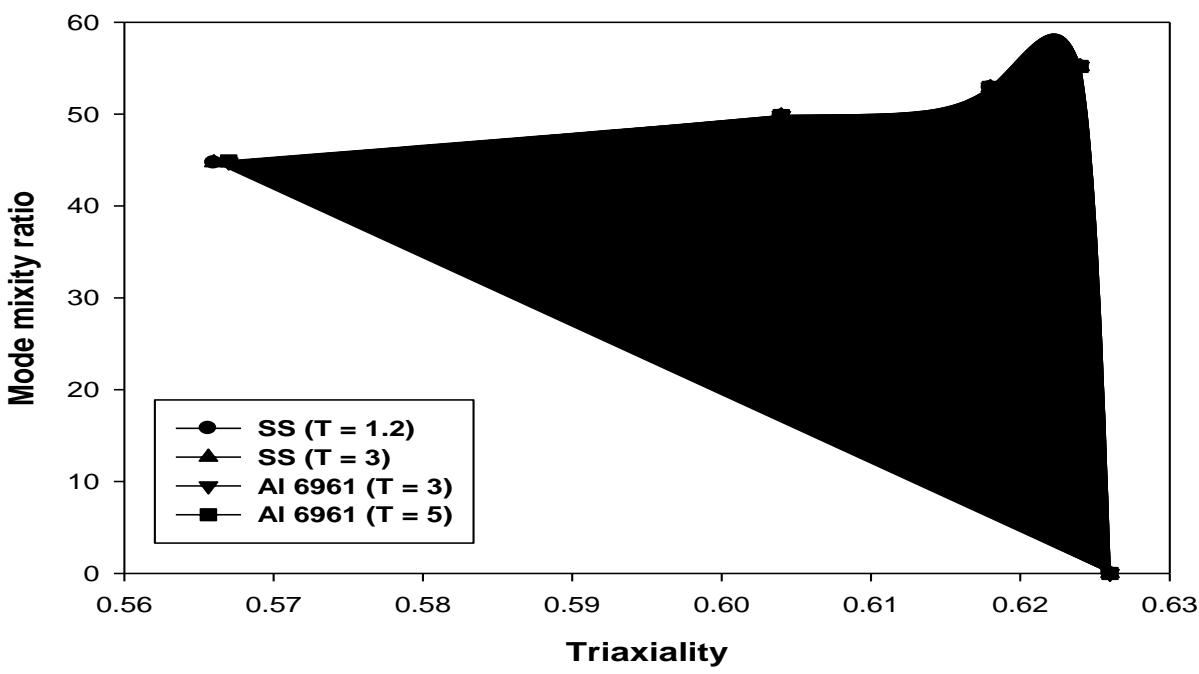

Fig 5 Variation of stress triaxiality with mode mixity ratio $\left(\mathrm{M}_{\mathrm{e}}\right)$ 


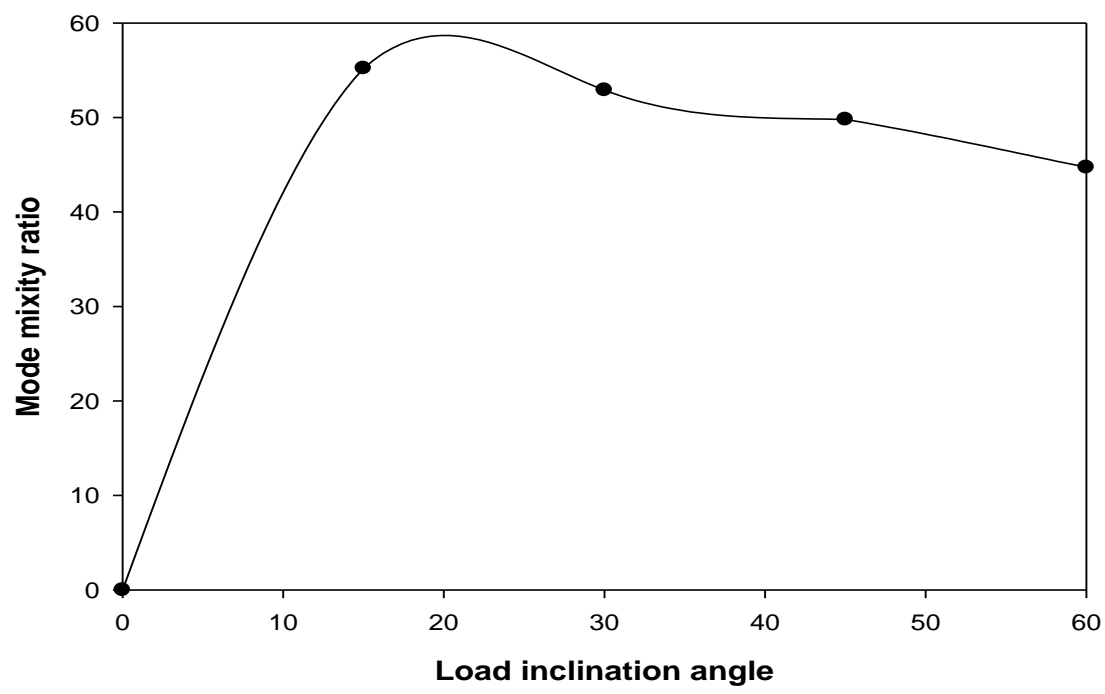

Fig 6 Variation of mode mixity ratio with load inclination angle

The following results obtained after the FE analysis in ANSYS shows that as the loading angle increases the region of maximum stress is also drifted with respect to the loading angle.In the following figures the stress distribution is shown by different colours

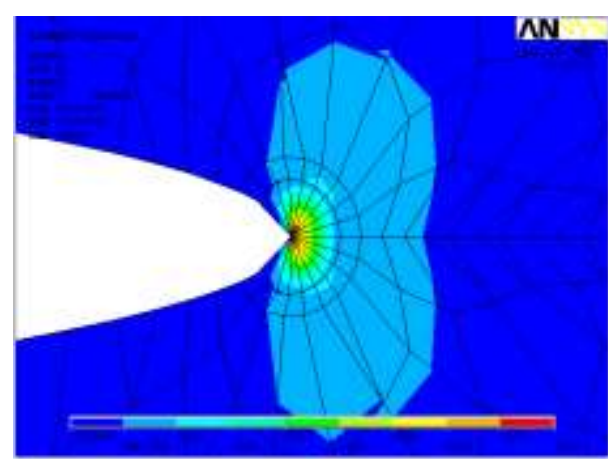

Fig 7

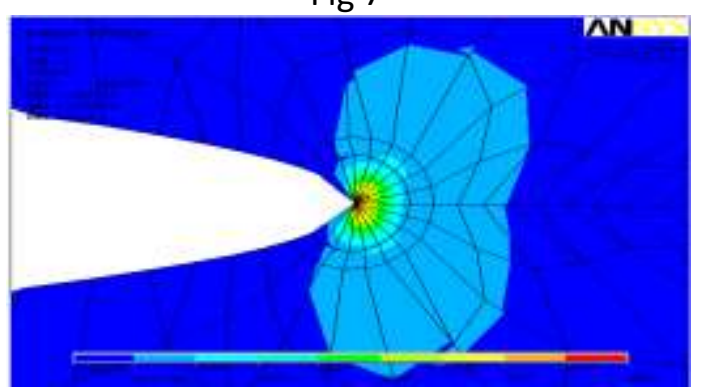

Fig 8

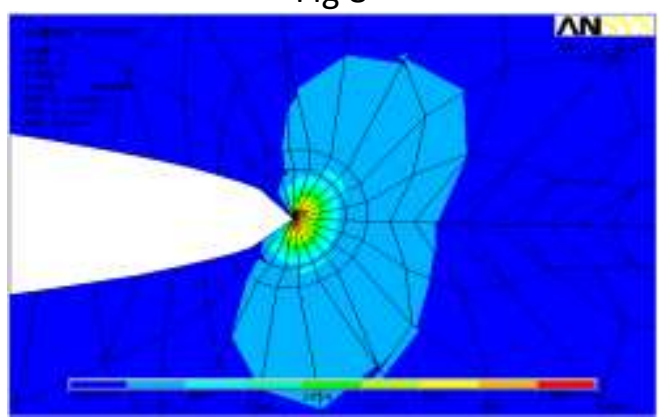

Fig 9 


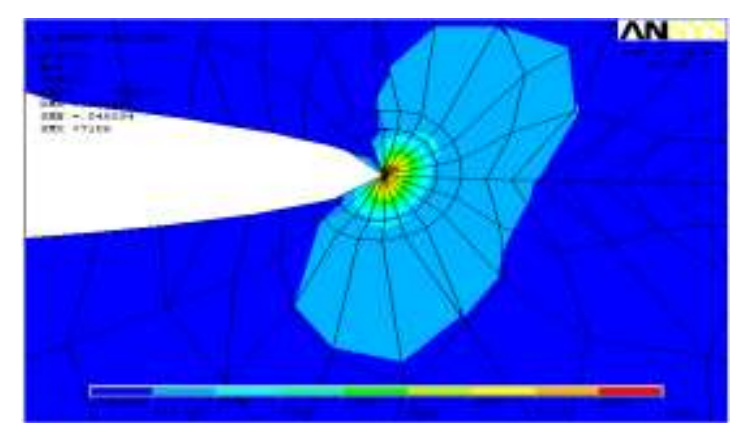

Fig 10

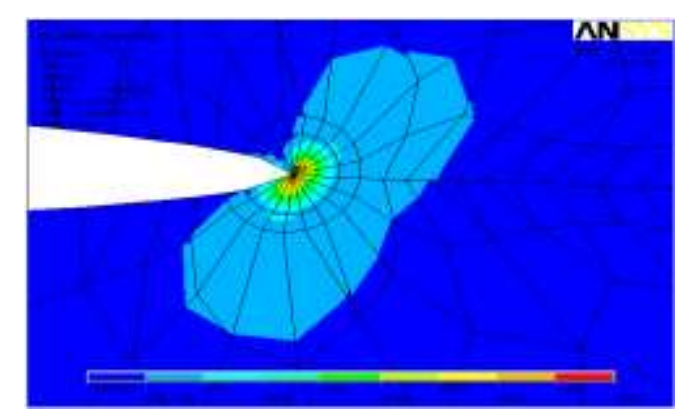

Fig 11

\section{CONCLUSION}

The comparative study of experimental work done by Maiti and Mahanti (1990) and numerical study of crack tip opening displacement for mode I and mixed mode (I/II) stable crack growth in thin sheets of SS304 and $\mathrm{Al} 6061$ has been carried out. The ratio between the maximum and initiation loads has been obtained in the range as available in the literature. It is investigated that stress triaxiality increases with increase in CTOD. Another finding shows that $\mathrm{M}_{\mathrm{e}}$ is independent of material property and geometry of the specimen but depends upon applied load. Thus, It can be concluded that the stress triaxiality and CTOD play vital role in crack propagation and initiation in isotropic materials

\section{REFERENCES}

D. K. MAHANTY AND S. K. MAITI (1990) EXPERIMENTAL AND FINITE ELEMENT STUDIES ON MODE I AND MIXED MODE (I AND II) STABLE CRACK GROWTH-I, EXPERIMENTAL ENGINEERING FRACTURE MECHANICS VOL. 37, NO. 6, PP. 1237-1250, 1990

[1] J. N. Robinson (1976), An experimental investigation of the effect of specimen type on the crack tip opening displacement and Jintegral fracture criteria, International Journal of Fracture, Vol. 12, No. 5, October

[2] A. M. Abdel mageed and R. K. Pandey (2001) mixed mode crack growth under static and cyclic loading in al-alloy sheets, Engineering Fracture Mechanic Vol. 40,No. 2, pp. 371-3851

[3] V. Srinivas and V. Vasudevan (1993) studies of mixed mode crack propagationin d16at aluminium alloy, Engineering Fracture Mechanics, Vol 45, No. 4, pp. 435-430, 1993

[4] J. N. Robinson and A. S. Tetelman (1975) The relationship between crack tip opening displacement, local strain and specimen geometry, International Journal of Fracture, Vol. 11, No. 3

[5] S. K. Maiti a.h. i. Mourad (1995), criterion for mixed mode stable crackgrowth - ii. Compact tension geometry with and without stiffener, Engineering Fracture Mechanics Vol. 52, No. 2, pp. 349-378, 1995

[6] S. K. Maiti and p. D. Savla (1993) experimental and finite element study on mode i stable crack growth in symmetrically stiffened compact tension specimen, Engineering Fracture Mechanics Vol. 44, No. 5, pp. 721-733, 1993

[7] S.K. Maiti, S. Namdeoa, A.H.I. Mourad (2008) A scheme for finite element analysis of mode I and mixed mode stable crack growth and a case study with AISI 4340 steel, Nuclear Engineering and Design 238 (2008) 787-800

[8] Sova bhat'tacharya and a. n. icumar (1991) a new approach for ctod evaluation ln slow crack growth situations, Engineering Fracture Mechanics Vol. 40, No. 6, pp. 108 1103

[9] Shailendra Singh Bhadauria, M.S. Hora, K.K. Pathak, (2009) Effect of Stress Triaxiality on Yielding of Anisotropic Materials under Plane Stress Condition, Journal of Solid Mechanics Vol. 1, No. 3 (2009) pp. 226-232

[10] Shailendra Singh Bhadauria, K.K. Pathak, M.S. Hora, (2012), Maximization of Stress Triaxiality along Yield Locus of Isotropic Ductile Materials under Plane Strain Condition, Journal of Material Science - Poland, (Article in Press)

[11] Shailendra Singh Bhadauria, K.K. Pathak, M.S. Hora, (2010), Finite Element Modeling of Crack Initiation Angle Under Mixed Mode (I/II) Fracture. Journal of Solid Mechanics, Vol. 2

[12] Y. Arun roy and R. Narasimhan (2000) $J$-Dominance in mixed mode ductile fracture specimens, International Journal of Fracture 88: $259-279$ 